

\section{GUIDELINES ON HOW TO SUCCESSFULLY DESIGN, AND IMPLEMENT, MISSION-ORIENTED RESEARCH PROGRAMMES}

Despite tremendous progress that our societies have made in recent decades, equally challenging tasks remain. These societal challenges directly concern the way we interact with each other and our environment, the way we produce and consume, and the way in which we construct and perceive meaning in our actions or change our behaviour.

Scientific research is an important driver for economic and social wellbeing. It provides analytical capacity and lays the groundwork for creating relevant and evidence-based policy solutions. It is thus not surprising that many research funding programmes aim at putting value in excellent research for tackling societal challenges.

Cooperation across and beyond different disciplinary backgrounds and with different (methodological, technological, theoretical) knowledge provides nuanced, multi-layered analyses and enables mitigation of grand challenges. That's why research funding programmes often ask specifically for interdisciplinary approaches, and for experts to look at problems from different perspectives.

\section{SSH research is crucial for success of programmes}

In fundamental aspects, research in social sciences and humanities (SSH) plays a crucial role in the success of any research funding programme that aims at tackling societal challenges:

Almost all of our current societal problems are influenced by different aspects of politics, social and cultural norms, ethics and legal frameworks, production and consumption patterns, traditions and life styles, and historic trajectories. To correctly identify and address the problem, those deep-running connections have to be analysed and understood. One can find aspects of political economy and a diversity of social and cultural dimensions in each research cluster, be it health, energy transition, climate change, bio-economy, or transport.

Similarly, if scientific research is expected to provide real solutions for ailments of humans or societies at large, it is important to study the - intended as well as unintended - impact of innovations and their potential rebound effects thoroughly. Innovation is anything new that creates some form of value - often economic, but not always. Value creation also happens by adopting innovations, which is basically a social process with various societal implications. Innovation is thus not just the business of business, but also the business of society, and, thus, also a line of action for SSH.

By now, the unique set of expertise, knowledge, and capacity that SSH holds for research in tackling societal challenges is fully acknowledged: better understanding of the social dimension to the challenges we face needs to be tackled at the same time as we seek to use technological advancement to solve problems. Europe has realised the untapped resource of $\mathrm{SSH}$ research and has the ambition to become a global pioneer of "integrating" SSH across its research funding programmes. The Lamy Report on "Horizon Europe" (starting 2021) emphatically states that "Missions ... will, by design, fully integrate social sciences and humanities (SSH)."1 The Competitiveness Council of the European Council agreed "that social sciences and humanities (SSH) shall play an important role across all clusters". ${ }^{2}$ Similarly, SSH communities have worked tirelessly in recent years to make themselves usable for addressing the societal challenges. ${ }^{3}$

\section{From "integration" to cooperation}

Yet so far, existing programmes have not entirely managed to unleash the full potential of interdisciplinary cooperation between SSH research

$1 \quad$ Pascal Lamy et al., “LAB-FAB-APP. Investing in the European Future We Want," Report of the independent High Level Group on maximising the impact of EU Research \& Innovation Programmes (Brussels: European Commission, July 2017), 16. doi:10.2777/477357.

2 See http://data.consilium.europa.eu/doc/document/ST-15102-2018-INIT/en/pdf, 10

3 Cf. Net4Society, ..Keys to successful integration of Social Sciences and Humanities in H2020“, https://www.net4society.eu/_ media/170110_Factsheet_Expert\%20meeting_INTEGRATION_def.pdf 


\section{GUIDELINES ON HOW TO SUCCESSFULLY DESIGN, AND IMPLEMENT, MISSION-ORIENTED RESEARCH PROGRAMMES}

and research from the natural sciences, technology, engineering, and mathematics (STEM). Monitoring of funded projects aiming at "integration" provides evidence of mixed results. Serious efforts must be strengthened to create a basis where SSH and STEM address global challenges together and on an equal footing. Thus far, $\mathrm{SSH}$ is often only brought in once the respective research task has already been framed or even only added-on at the end of a project - as if it were a consultancy service to make publics love the technologies that are being developed. However, framing a specific problem or mission omitting insights from SSH may prove detrimental, thus integration from the very beginning is essential.

A programme which identifies the connected nature of technological and human and social dimensions will have gone a long way to overcoming the hurdle for being successful and effective. For researchers from SSH being enabled to truly cooperate with their STEM colleagues, the efforts for achieving an equal footing have to be increased - at two levels. One concerns the level of implementing research programmes, as has been done already. At this level, much insight can be drawn from recent experiences. The other concerns the level of designing research programmes - and this is where little experience exists thus far and where more active involvement of $\mathrm{SSH}$ communities is needed.

This suggests two necessary avenues for SSH research to have the best chance of maximising its contribution to tackling societal challenges.

\section{Stimulating and enabling cooperation when designing a research funding programme}

When designing a new research funding programme, or when refurbishing an existing one, it is of utmost importance to co-determine agendas and priorities with insights and expertise from SSH researchers in an atmosphere of mutual respect. This section is intended to speak directly to policy makers and managers of funding bodies who together with external stakeholders - usually define the overall goals of funding programmes, and who set aside budgets for funding research to achieve the desired goals. Those managers setting up such programmes have to recognise the differences of the fields and their own potentials, and that they can make use of practical guidance for achieving terms under which successful cooperation will occur and increase.

\section{WHAT DOES SSH RESEARCH BRING TO THE TABLE?}

"SSH" covers a broad field of academic disciplines and scientific areas. Because SSH research is as diverse as our societies, cultures, and economies are, it frames and co-shapes transformative aspects of research and contributes to integrating complex cross-domain perspectives and standpoints, including those from other scientific disciplines and non-academic actors. From this breadth and diversity, we can identify the multidimensional strengths of research in the social sciences and humanities:

- The expertise to calibrate missions, highlighting priority aspects to focus on "what matters"

- The capacities of translating between academic disciplines, policy-makers and different publics

- The expertise in placing specific problems in broader contexts, integrating both local and global perspectives

- The long-standing tradition of methodological reflexivity, recognising social and cultural influences on research itself

\section{PRACTICAL TIPS FOR UNLEASHING THE FULL POTENTIAL OF INTERDISCIPLINARY COOPERATION TO TACKLE SOCIETAL CHALLENGES}

- Bring members of different scientific fields to your advisory bodies, and specifically those from SSH research fields, to co-determine the goals of the research funding programme you are about to establish.

- Regard SSH research not as a critical add-on, but as a vital contribution to correctly 


\section{GUIDELINES ON HOW TO SUCCESSFULLY DESIGN, AND IMPLEMENT, MISSION-ORIENTED RESEARCH PROGRAMMES}

understanding the problem at hand, and for implementing the resulting solution appropriately. This way, cooperation with SSH research will automatically shift from being "mandatory" to being obvious and fruitful.

- Grant respect equally to scientists and researchers from SSH as from STEM; trust the discursive powers of interdisciplinary negotiations and the expertise of SSH research in processes of cocreation.

- Be generous with stipulations concerning interdisciplinary cooperation, as it requires time and space for researchers from different backgrounds to become acquainted.

\section{Fostering}

\section{cooperation while implementing a research funding programme}

Once a research funding programme is implemented, it is mandatory to make sure that $\mathrm{SSH}$ research is taken into account. Thus, this section is directed specifically at

- officers and managers within funding agencies establishing and executing funding programmes

- panellists and reviewers providing expertise and judgement for decision-making in the execution of funding programmes

- independent evaluators of those funding programmes

\section{IF YOU ARE A PROGRAMME OFFICER}

- Make funding calls inclusive! Throughout the text of a call, explain that the social dimensions of a specific challenge need to be addressed alongside other aspects.

- Define criteria that encourage jury panellists and reviewers to identify the right people - not necessarily those with the formally best track and publication record. Metrics, rankings, or indicators may serve as means for decisionmaking, but should not serve as a universal panacea. ${ }^{4}$

- Increase variation! Involve experts (plural!) from SSH in the evaluation procedures of your calls.

- Encourage SSH researchers proactively to compete for funding, and to lead projects and consortia.

\section{IF YOU ARE A PANELLIST, OR A REVIEWER}

- Take context into account! Local and/or contextualised expertise from SSH may be more valuable for a project than "global" recognition of any scholar. Don't fall for the ubiquity of excellence rhetoric!

- Allow for original proposals that include, or are led by, $\mathrm{SSH}$ researchers. Respect the autonomy of SSH researchers to bring in their own ways of working to projects they are leading.

- Academic disciplines have different sizes and express their hierarchies differently. Do not believe the patina of precision, projected by metrics, as they often suggest impact where there is none.

- Look beyond potential scientific impact and consider also potential transformative societal, economic, political, ecological or cultural impact.

\section{IF YOU ARE AN INDEPENDENT PROGRAMME EVALUATOR}

- Look out for difference! There are different types of impact, and that they may be longterm as well as immediate. Ideas and concepts take time to ripple out from initial academic communities into society.

- Make sure the programme scope and call texts consider the social dimensions of the societal challenge to be tackled, and compare with the call winning teams and their composition.

- Account for the reflexive dimension of the programme, and look out for what social 


\section{GUIDELINES ON HOW TO SUCCESSFULLY DESIGN, AND IMPLEMENT, MISSION-ORIENTED RESEARCH PROGRAMMES}

values are inscribed into the programme.

- $\quad$ Check the types of cooperation that are projected and actually take place, and to what degree participation and communication across and beyond disciplines are made possible.

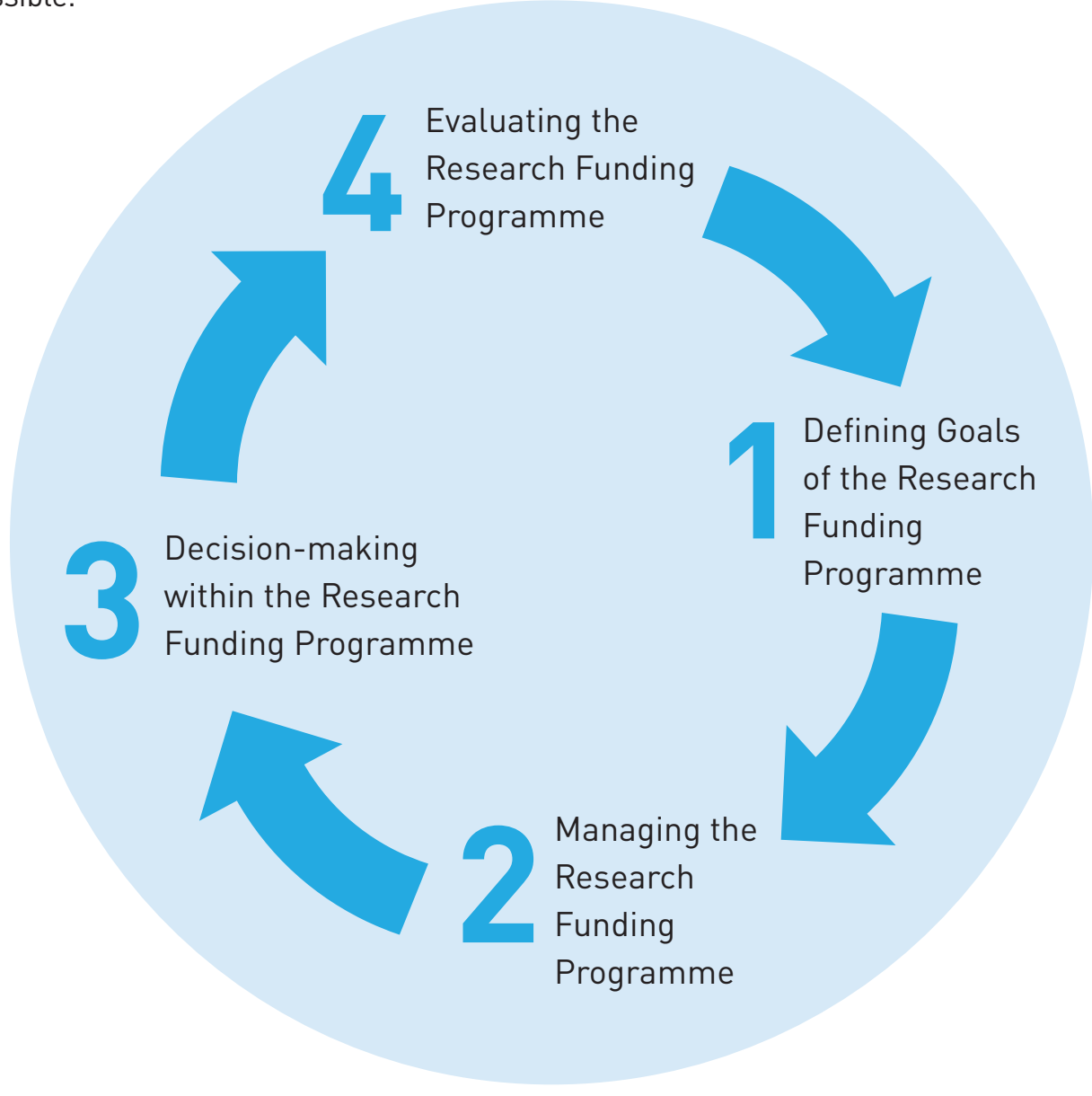

\section{To whom are these guidelines addressed?}

This document is directed at all people who deal - in one way or another - with research funding programmes. Specifically (but not exclusively), these guidelines address research programmes that set out a specific goal to tackle a societal problem through the means and opportunities provided by scientific and scholarly research - both from SSH and STEM. The expected research is often described as "mission-oriented", albeit usage of this term differs. 
